\title{
Acute Liver Injury in Patients Hospitalized with COVID-19
}

\author{
Lindsay A. Sobotka ${ }^{1}$ (D) James Esteban ${ }^{2} \cdot$ Michael L. Volk ${ }^{3} \cdot$ B. Joseph Elmunzer ${ }^{4,5}$ - Don C. Rockey ${ }^{4,5} \cdot$ for the North \\ American Alliance for the Study of Digestive Manifestation of COVID-19*
}

Received: 9 May 2021 / Accepted: 15 August 2021 / Published online: 6 September 2021

(c) The Author(s), under exclusive licence to Springer Science+Business Media, LLC, part of Springer Nature 2021

\begin{abstract}
Introduction The prevalence and significance of acute liver injury in patients with COVID-19 are poorly characterized. Methods Patients with confirmed COVID-19 who were hospitalized in geographically diverse medical centers in North America were included. Demographics, symptoms, laboratory data results, and outcomes were recorded. Linear and logistic regression identified factors associated with liver injury, in-hospital mortality, and length of stay (LOS).

Results Among 1555 patients in the cohort, most (74\%) had an elevated alanine aminotransferase (ALT) during hospitalization, which was very severe (>20 $\times$ upper limit of normal [ULN]) in $3 \%$. Severe acute liver injury (ALI) was uncommon, occurring in $0.1 \%$ on admission and $2 \%$ during hospitalization. No patient developed acute liver failure (ALF). Higher ALT was associated with leukocytosis (per $\left.\mathrm{mL}^{3}\right)(\beta$ 10.0,95\% confidence interval (CI) 6.7-12.6, $p<0.001)$ and vasopressors use $(\beta$ 80.2, 95\% CI 21.5-138.8, $\mathrm{p}=0.007$ ). In-hospital mortality was associated with ALT $>20 \times \mathrm{ULN}$ (unadjusted OR 6.0, 95\%CI 3.1-11.5, $p<0.001$ ), ALP $>3 \times$ ULN (unadjusted OR 4.4, 95\%CI 2.5-7.7, $p<0.001$ ), and severe ALI (unadjusted OR 6.8, 95\% CI 3.0-15.3, $p<0.001$ ) but lost significance after adjusting for covariates related to severe COVID-19 and hemodynamic instability. Elevated ALP and ALT were associated with longer LOS, admission to intensive care, mechanical ventilation, vasopressor use, and extracorporeal membrane oxygenation use $(p<0.001)$.

Conclusions Transaminase elevation is common in hospitalized patients with COVID-19. Severe ALI is rare, and ALF may not be a complication of COVID-19. Extreme elevations in liver enzymes appear to be associated with mortality and longer LOS due to more severe systemic disease rather than SARS-CoV-2-related hepatitis.
\end{abstract}

Keywords Transaminase $\cdot$ Alkaline phosphatase $\cdot$ Bilirubin $\cdot$ Acute liver failure $\cdot$ Outcomes

\section{Introduction}

*Full list of authors in Appendix 1

Lindsay A. Sobotka

lindsay.sobotka@osumc.edu

1 Division of Gastroenterology, Hepatology and Nutrition, Department of Internal Medicine, The Ohio State University Wexner Medical Center, 395 West 12th Avenue, Floor 2, Columbus, OH 43210, USA

2 Division of Gastroenterology, Hepatology and Nutrition, Department of Internal Medicine, Medical College of Wisconsin, Milwaukee, WI, USA

3 Division of Gastroenterology and Transplant Institute, Loma Linda University Health, Loma Linda, CA, USA

4 Division of Gastroenterology and Hepatology, The Medical University of South Carolina, Charleston, SC, USA

5 Digestive Disease Research Center, The Medical University of South Carolina, Charleston, SC, USA
In November 2019, a cluster of patients with a severe, atypical pneumonia were identified in mainland China. Investigation of these cases resulted in the identification of a novel severe acute respiratory syndrome coronavirus-2 (SARSCoV-2) virus that is responsible for coronavirus disease 2019 (COVID-19) infection [1-3]. The clinical presentation of COVID-19 ranges from asymptomatic to a severe infection characterized by multisystem organ failure with need for mechanical ventilation, vasopressor support, or extracorporeal membrane oxygenation (ECMO) that can result in death [4-7].

It has been reported that a large proportion of hospitalized patients with COVID-19 develop abnormal liver enzymes [4, $5,8-11]$. Over $50 \%$ of patients hospitalized for COVID-19 appear to have at least one abnormal liver enzyme on admission, and over $75 \%$ will develop abnormal liver enzymes 
over the course of hospitalization. These abnormalities are typically an elevation in aminotransferases between 1 and 3 times ( $\mathrm{x}$ ) the upper limit of normal (ULN), although a small number of patients have been reported to experience transaminases greater than $10 \times$ the ULN $[5,8,12,13]$. Several case reports have promulgated the concept that COVID19 is associated with severe acute livery injury (ALI) and acute liver failure (ALF) [13-15]. Currently, it remains unclear whether SARS-CoV-2 is truly a hepatotropic virus or whether abnormal liver enzymes are a reflection of a systemic inflammatory syndrome and/or severe sepsis [9].

The clinical significance of liver enzyme abnormalities, specifically their correlation to COVID-19 disease severity (i.e., the need for intensive care and mortality), has been controversial $[8,12]$. While it is suspected that severe elevations in transaminases correlate with increasing COVID-19 severity, this remains uncertain based on the current literature. In this study, we aimed to determine the prevalence and severity of liver enzyme abnormalities in a large population of patients hospitalized with COVID-19 at an alliance of geographically diverse medical centers across North America and also to determine whether SARS-CoV-2 caused severe ALI and/or ALF.

\section{Methods}

\section{Data Source and Study Design}

This was an observational cohort study that utilized information from patients hospitalized at 36 geographically diverse medical centers throughout North America during the earliest phase of the pandemic [5]. Each center obtained institutional review board approval prior to patient identification and data collection.

\section{Study Sample}

Adult patients were eligible for review if they were hospitalized and were documented to have COVID-19 through either rapid viral testing or polymerase chain reaction (PCR). Eligible patients were identified by site investigators utilizing multiple methods including data warehouse queries, electronic research identification tools, and lists provided by infectious diseases services. Depending on the number of hospitalized patients with COVID-19 at each institution, the first 50 to 100 consecutive hospitalized patients with documented COVID-19 were included to ensure a systemic and unbiased sample. Patients were excluded from this analysis if liver tests were not recorded on admission or during hospitalization (Supplementary Fig. 1).

\section{Data Collection and Quality Assurance}

De-identified data were directly entered into an electronic data collection form by study personnel under direct supervision of a clinician investigator at each institution. Multiple interventions were instituted to ensure data quality and veracity. Once data were received by the data coordinating center (Medical University of South Carolina), they were manually reviewed by a dedicated data manager. Missing or duplicate data, inconsistencies, outlier data, and conflicting results were directly queried to the site until resolution.

\section{Variables and Definitions}

Demographics, laboratory test results on admission and peak laboratory abnormalities during hospitalization, radiographic data, presenting symptoms, medical comorbidities, treatments received for COVID-19, and patient outcomes were collected for each patient as previously described. Patients with severe acute livery injury also had assessment of their mental status using the West Haven criteria [16].

Elevation in serum transaminases was defined as normal, mild $(1-3 \times \mathrm{ULN})$, moderate $(3-10 \times \mathrm{ULN})$, severe $(10-20 \times U L N)$, or very severe $(>20 \times U L N)$. The ULN of alanine aminotransferase (ALT) was defined as $29 \mathrm{U} / \mathrm{L}$ for men and $22 \mathrm{U} / \mathrm{L}$ for women [17]. Elevation of alkaline phosphatase (ALP) was defined as normal, mild (1-2×ULN), moderate $(2-3 \times \mathrm{ULN})$, or severe $(>3 \times \mathrm{ULN})$. ULN of ALP was defined as $120 \mathrm{IU} / \mathrm{L}$ [17-19].

In patients with at least moderate elevation of ALT $(>3 \times \mathrm{ULN})$ or at least moderate elevation of ALP $(>2 \times \mathrm{ULN})$, pattern of liver injury was further characterized as hepatocellular ( $R$ factor $\geq 5)$, cholestatic ( $R$ factor $\leq 2)$, or mixed ( $\mathrm{R}$ factor 2-5) [20]. Severe ALI was defined as ALT greater than $10 \times \mathrm{ULN}$ with total bilirubin greater than $2 \mathrm{mg} /$ dL. Acute liver failure (ALF) was defined as the presence of severe ALI with altered mental status in the absence of preexisting liver disease as previously defined [21]. Only $60 \%$ of patients had reported admission and peak international normalized ratio (INR), and thus, INR was not included in our definition of severe ALI and ALF to avoid excluding a significant portion of the sample. Sites that contributed data on patients who meet criteria for severe ALI were queried whether, based on their clinical judgment, severe ALI was due to SARS-CoV-2 and whether the patient met clinical criteria for ALF.

\section{Study Outcomes}

The primary study outcome was the prevalence of abnormal liver enzymes and liver injury in patients hospitalized 
with COVID-19. Secondary outcomes included severe ALI or ALF, in-hospital mortality, discharge to skilled nursing facility (SNF), hospital length of stay (LOS), and intensive care requirements (mechanical ventilation, vasopressor use, and/or ECMO).

\section{Statistical Analysis}

Continuous and categorical variables were summarized as means, median, and proportions. Patient groups were compared using analysis of variance and Chi-square for continuous and categorical variables, respectively. Independent predictors of peak ALT, peak ALP, and severe ALI were analyzed through stepwise backward regression that used a cutoff $p$-value of 0.1 for inclusion in the final model. Predictor variables included demographic data (e.g., age, sex, race, smoking, and BMI), comorbidities, laboratory test values (e.g., peak white blood cell count, nadir hemoglobin, and nadir platelet count), markers of hemodynamic instability (e.g., need for vasopressors, mechanical ventilation, and ECMO), and markers of organ failure (e.g., AKI). The association of peak ALT, peak ALP, and severe ALI to inhospital mortality and hospital LOS was examined using hierarchical multiple logistic and linear regression where separate covariable blocks composed of demographic features, medical comorbidities, and markers of critical illness were sequentially added to the regression model. Model 1 is composed of demographic covariables, model 2 is composed of model 1 plus comorbidity variables, and model 3 (fully adjusted model) is composed of model 2 plus hemodynamic instability and organ failure variables. A subgroup analysis was performed using discharge to SNF as outcome utilizing the same regression models, but which excluded patients who died or were still hospitalized at the end of the observation period $(n=1224)$. Kaplan-Meier curves were fit to evaluate inpatient mortality based on admission ALT, ALP, or pattern of liver injury. Statistical analyses were performed using Stata v14.2 (StataCorp, College Station, TX).

\section{Results}

Data were collected on 1992 patients hospitalized with COVID-19. A total of 437 patients were excluded due to missing admission and peak ALT or ALP, leaving 1555 patients (78\%) for analysis (Table 1, Supplementary Table 1, Supplementary Fig. 1).

\section{Prevalence of Abnormal Liver Tests}

A majority of patients (53\%) had an elevated ALT on admission, which was mild in most cases (45\%). No patient had a very severe elevation in ALT on admission.
Table 1 Characteristics of the study cohort $(n=1555)$

\begin{tabular}{|c|c|}
\hline Mean age (SD) & $60(16)$ \\
\hline Male sex, n (\%) & $879(57)$ \\
\hline \multicolumn{2}{|l|}{ Race, $n(\%)$ (unspecified 17\%) } \\
\hline Black & $684(44)$ \\
\hline White & $571(37)$ \\
\hline Other & $44(3)$ \\
\hline Hispanic, n (\%) & $251(16)$ \\
\hline Healthcare worker, $n(\%)$ (missing 11\%) & $93(6)$ \\
\hline \multicolumn{2}{|l|}{ Smoking, n (\%) (unknown 5\%) } \\
\hline Current & $107(7)$ \\
\hline Former & $418(27)$ \\
\hline Never & $946(61)$ \\
\hline \multicolumn{2}{|l|}{ Alcohol use, $n(\%)$ (unknown 10\%) } \\
\hline Current & $147(10)$ \\
\hline Former & $83(5)$ \\
\hline Never & $1163(75)$ \\
\hline Mean BMI (SD) (missing 6\%) & $32(9)$ \\
\hline \multicolumn{2}{|l|}{ Comorbidities, n (\%) } \\
\hline Hypertension & $994(64)$ \\
\hline Diabetes mellitus & $587(38)$ \\
\hline Cardiovascular disease* & $453(29)$ \\
\hline Chronic lung disease ${ }^{* *}$ & $426(27)$ \\
\hline End-stage renal disease & $155(10)$ \\
\hline Cancer & $95(6)$ \\
\hline Dementia & $86(6)$ \\
\hline Connective tissue disease & $83(5)$ \\
\hline HIV & $25(2)$ \\
\hline Chronic liver disease, $n(\%)$ & $55(4)$ \\
\hline Viral hepatitis & $20(36)$ \\
\hline Nonalcoholic fatty liver disease & $15(27)$ \\
\hline Alcohol & $4(7)$ \\
\hline Other*** & $36)$ \\
\hline Unspecified & $13(4)$ \\
\hline Cirrhosis, n (\%) & $21(1)$ \\
\hline Decompensated cirrhosis, n (\%) & $7(1)$ \\
\hline \multicolumn{2}{|l|}{ Lab tests } \\
\hline Peak WBC (SD) (missing 0.2\%) & $13(9)$ \\
\hline Nadir WBC (SD) (missing 0.3\%) & $5(3)$ \\
\hline Nadir hemoglobin (SD) (missing 0.2\%) & $10(3)$ \\
\hline Nadir platelet (SD) (missing 0.3\%) & $17(82)$ \\
\hline Peak creatinine (SD) (missing 1\%) & $2.4(3)$ \\
\hline \multicolumn{2}{|l|}{ Liver tests } \\
\hline Admission AST, U/L (SD) & $51(6)$ \\
\hline Peak AST, U/L (SD) & $191(1099)$ \\
\hline Admission ALT, U/L (SD) & $37(36)$ \\
\hline Peak ALT, U/L (SD) & $119(452)$ \\
\hline Admission ALP, U/L (SD) & $82(53)$ \\
\hline Peak ALP, U/L (SD) & $123(119)$ \\
\hline Admission total bilirubin, mg/dL (SD) & $0.6(0.7)$ \\
\hline Peak total bilirubin, mg/dL (SD) & $1.7(10)$ \\
\hline Admission INR (SD) (missing 50\%) & $1.3(1)$ \\
\hline
\end{tabular}


Table 1 (continued)

\begin{tabular}{ll}
\hline Peak INR (SD) (missing 35\%) & $1.5(1)$ \\
Acute kidney injury, $\mathrm{n}(\%)$ & $228(15)$ \\
(Peak Cr $>2 \times$ admission Cr+no history of ESRD) & \\
Abdominal imaging, $n(\%)$ & $244(16)$ \\
Computed tomography & $199(13)$ \\
Ultrasound & $65(4)$ \\
Magnetic resonance imaging & $5(0.3)$ \\
Received SARS-CoV-2 treatment, $n(\%)$ & $1197(77)$ \\
Hydroxychloroquine & $848(55)$ \\
Azithromycin & $823(53)$ \\
Corticosteroids & $186(12)$ \\
Tocilizumab & $101(7)$ \\
Remdesivir & $97(6)$ \\
Convalescent plasma & $32(2)$ \\
\hline
\end{tabular}

Abbreviations: $\mathrm{ALP}=$ alkaline phosphatase, $\mathrm{ALT}=$ alanine aminotransferase, $\mathrm{BMI}=$ body mass index, $\mathrm{Cr}=$ creatinine, $\mathrm{ESRD}=$ endstage renal disease, INR = international normalized ratio, SD-standard deviation, $\mathrm{WBC}=$ white blood cell

*Cardiovascular disease is a composite of the following

Coronary artery disease 231 (15)

Heart failure 192 (12)

Stroke 141 (9)

Peripheral vascular disease 77 (5)

**Chronic lung disease is a composite of the following

Asthma 188 (12)

COPD 132 (9)

OSA $171(11)$

Interstitial lung disease 15 (1)

Pulmonary hypertension 10 (1)

***Other liver disease includes autoimmune hepatitis (1), hemochromatosis (1), and cardiac cirrhosis (1)

Overall, $74 \%$ of patients developed an elevation in ALT during hospitalization, most of which were mild elevation (45\%); however, 43 (3\%) developed pronounced peak elevations in ALT (Fig. 1). Virtually all patients had normal or, at most, mildly elevated ALP (normal $88 \%$, mild elevation $11 \%$ ) on admission, and most (70\%) continued to have normal ALP during hospitalization. Of those who had elevated peak ALP levels, most were mild elevations; however, 56 (4\%) developed a severe elevation in ALP (Fig. 1B). Bilirubin levels were typically normal on presentation, and only a mild elevation was noted on peak laboratory analysis (Table 1). Only $270(17 \%)$ patients had a liver injury defined as at least moderate elevation in ALT or any elevation in ALP on admission which increased to 677 (44\%) during the course of hospitalization. Liver injury on admission was cholestatic in $10 \%$, hepatocellular in 5\%, and mixed in 3\%. Peak liver injury was hepatocellular in $17 \%$, cholestatic in $16 \%$, and mixed in $11 \%$ (Fig. 1C).

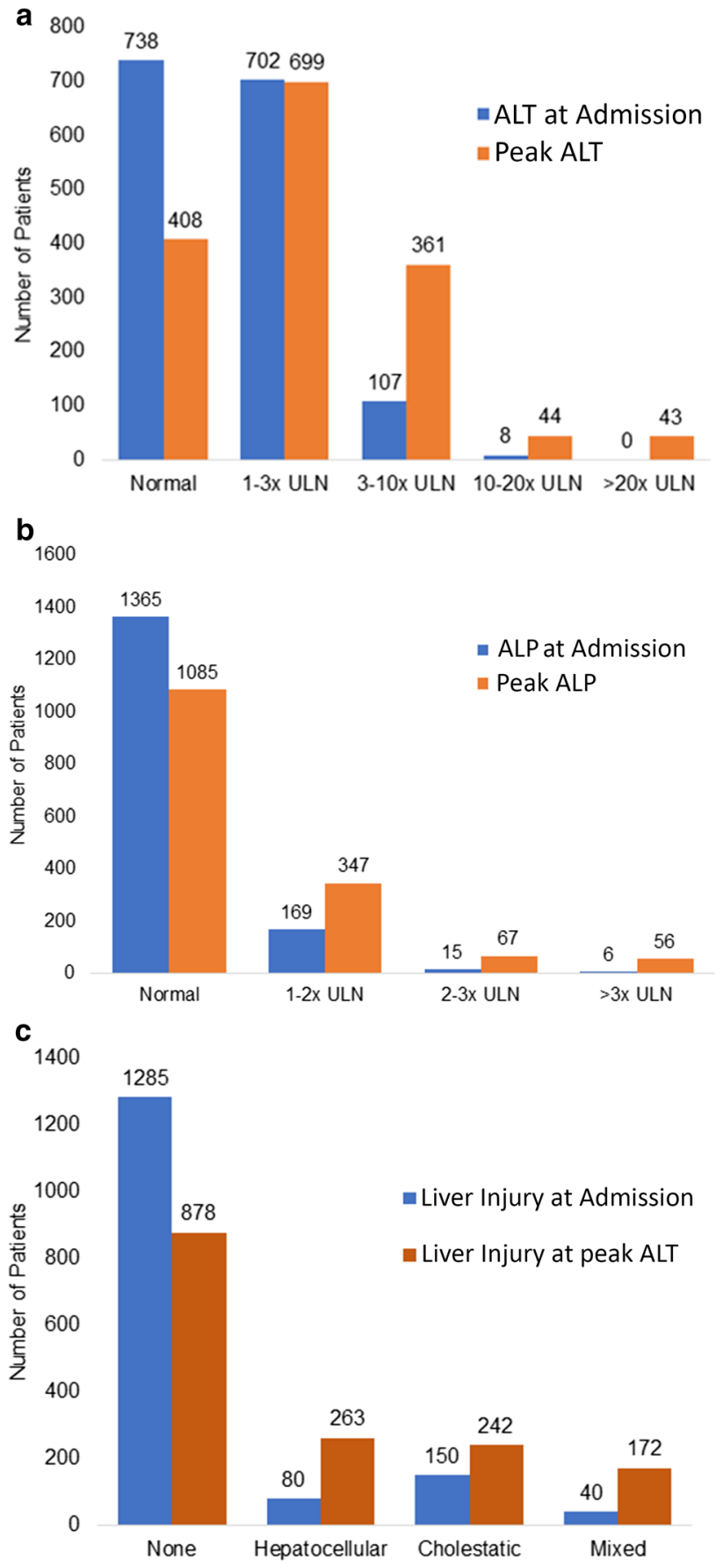

Fig. 1 Frequency of liver test abnormalities and liver injury patterns. In $\mathbf{a}$ and $\mathbf{b}$ are shown the number of patients with abnormal alanine aminotransferase (ALT) or alkaline phosphatase (ALP) (of the total $1,555)$ at admission or at peak. In $\mathbf{c}$ liver injury (defined as hepatocellular, cholestatic or mixed) based on $\mathrm{R}$ factor at the time of admission and at peak are shown 


\section{Predictors of Abnormal ALT and ALP}

On multivariable analysis, peak ALT was independently associated with leukocytosis, need for vasopressor support, and presence of end-stage renal disease, while peak ALP was independently associated with leukocytosis, anemia, thrombocytopenia, acute kidney injury (AKI), low BMI, Hispanic ethnicity, and need for vasopressors (Table 2).

\section{Patient Outcomes}

Out of 1,555 patients, $19 \%$ died in the hospital, while $65 \%$ were discharged to home and $15 \%$ were discharged to a care facility. Median hospital LOS was $13 \pm 12$ days. Forty-seven percent were admitted in intensive care for a mean duration of $13 \pm 11$ days. Mechanical ventilation, vasopressors, and ECMO were needed in $35 \%, 30 \%$, and $1 \%$, respectively (Table 3).

\section{Association Between In-Hospital Mortality and Peak Abnormal ALT and ALP}

In-hospital mortality was not significantly different based on ALT or ALP elevations on presentation ( $\mathrm{p} 0.196$ and $\mathrm{p}$ 0.090, respectively) (Table 3A, Fig. 2A, B). A significantly higher proportion of patients with very severe elevation in peak ALT or ALP died in the hospital (58\% vs. $<20 \%$ for ALT vs. those with less severe ALT elevation, $\mathrm{p}<0.001$ and $41 \%$ vs. $14 \%$ for ALP vs. those with less severe ALP elevation, $\mathrm{p}<0.001$, respectively) (Table 3B). Patients with moderate-to-severe elevations in peak ALT or elevated ALP had a greater frequency of ICU admission, mechanical ventilation, vasopressor use, and ECMO use. The severity of elevation in ALT or ALP on admission did not appear to be associated with in-hospital mortality (Table 3 ).
On univariable regression, patients with very severe elevation in peak ALT had sixfold higher risk and patients with severe elevation in peak ALP had fourfold higher risk of in-hospital mortality compared to patients with normal liver enzymes. The association between peak ALT and ALP elevation and in-hospital mortality remained statistically significant after adjusting for demographic variables and comorbidities. Statistical significance was lost after adjusting for covariables of hemodynamic instability and organ failure (e.g., AKI and need for vasopressors) (Table 4A). In the fully adjusted models, age, non-white and non-black race, underlying cancer or dementia, development of AKI, and need for vasopressors or mechanical ventilation predicted in-hospital mortality (Supplementary Tables 3 and 4).

\section{Association Between Hospital Length of Stay and Peak Abnormal Liver Enzymes}

Hospital LOS was twice longer in patients with severe and very severe elevation in ALT. Patients with any elevation in peak ALP also had longer hospital LOS. Severity of elevations in ALT or ALP on admission was not associated with hospital LOS (Table 3). Adjusting for demographic and comorbidity variables did not diminish the magnitude and statistical significance of the association between elevation in peak ALT and ALP and hospital LOS. After adjusting for variables related to hemodynamic instability in the fully adjusted model, very severe elevation in peak ALT was no longer associated with hospital LOS; associations in patients with less severe elevations in peak ALT remained significant. Adjusting for variables related to hemodynamic instability also decreased the magnitude of associations between peak ALP and hospital LOS, but these remained significant and showed a trend toward longer LOS with more severe elevation in peak ALP (Table 4B).

Table 2 Predictors of elevated ALT and ALP and liver injury in hospitalized patients with COVID-19

\begin{tabular}{|c|c|c|c|c|c|c|}
\hline \multirow[t]{2}{*}{ Variables } & \multicolumn{6}{|c|}{ Fully adjusted regression model } \\
\hline & Peak ALT beta $(95 \% \mathrm{CI})$ & $p$-value & Peak ALP beta $(95 \% \mathrm{CI})$ & $p$-value & Severe ALI OR (95\% CI) & $p$-value \\
\hline WBC count (per mL ${ }^{3}$ ) & $9.7(6.7-12.6)$ & $<0.001$ & $2.8(2.0-3.5)$ & $<0.001$ & $1.0(1.01-1.1)$ & 0.015 \\
\hline Hemoglobin (g/dL) & $N S$ & & $-6.5(-9.1$ to -3.9$)$ & $<0.001$ & $N S$ & \\
\hline Platelet count (per $10^{9} / \mathrm{L}$ ) & $N S$ & & $-0.1(-0.2$ to -0.02$)$ & 0.013 & $1.0(0.98-1.0)$ & 0.001 \\
\hline African-American race & $N S$ & & $N S$ & & $2.5(1.01-6.1)$ & 0.047 \\
\hline Hispanic ethnicity & $N S$ & & $26.5(10.8-42.2)$ & 0.001 & $N S$ & \\
\hline BMI (per unit) & $N S$ & & $-1.3(-2.0$ to -0.6$)$ & $<0.001$ & $N S$ & \\
\hline AKI & $N S$ & & $19.9(2.3-37.4)$ & 0.027 & $N S$ & \\
\hline ESRD & $106.3(27.6-185.1)$ & 0.008 & $N S$ & & $N S$ & \\
\hline Vasopressor requirement & $80.1(21.5-138.8)$ & 0.007 & $18.8(3.7-33.9)$ & 0.015 & $4.2(1.4-12.5)$ & 0.009 \\
\hline
\end{tabular}

Abbreviations: $\mathrm{AKI}=$ acute kidney injury, $\mathrm{ALI}=$ acute liver injury, $\mathrm{ALP}=$ alkaline phosphatase, $\mathrm{ALT}=$ alanine aminotransferase, $\mathrm{BMI}=\mathrm{body}$ mass index, $\mathrm{CI}=$ confidence interval, $\mathrm{ESRD}=$ end-stage renal disease, $\mathrm{OR}=$ odds ratio, $\mathrm{NS}=$ not significant, $\mathrm{WBC}=$ white blood cell 
Table 3 Outcomes in hospitalized patients with COVID-19 and relationship to liver tests and injury

\begin{tabular}{|c|c|c|c|c|c|c|c|c|c|c|c|}
\hline & \multicolumn{6}{|c|}{ ALT (times ULN) } & \multicolumn{5}{|c|}{ ALP (times ULN) } \\
\hline & Normal & $1-3 x$ & $3-10 x$ & $10-20 x$ & $>20 x$ & $p$-value & Normal & $1-2 x$ & $2-3 x$ & $>3 x$ & $p$-value \\
\hline \multicolumn{12}{|c|}{ A. Admission ALT and ALP values } \\
\hline Mean LOS, days (SD) & $14(12)$ & $13(12)$ & $13(14)$ & $16(13)$ & - & 0.634 & $13(12)$ & $15(15)$ & $16(12)$ & $7.3(5)$ & 0.203 \\
\hline \multicolumn{12}{|l|}{ Critical care needs } \\
\hline ICU admission, $\%$ & 44 & 50 & 43 & 75 & - & 0.069 & 46 & 52 & 60 & 17 & 0.180 \\
\hline ICU LOS, days (SD) & $12(11)$ & $13(10)$ & $14(11)$ & $16(4)$ & - & 0.776 & $13(10)$ & $12(12)$ & $14(13)$ & $7(0)$ & 0.903 \\
\hline Mech. ventilation, $\%$ & 34 & 36 & 31 & 75 & - & 0.069 & 34 & 37 & 47 & 17 & 0.505 \\
\hline Vasopressors, \% & 29 & 32 & 22 & 75 & - & 0.004 & 30 & 31 & 4 & 3 & 0.829 \\
\hline ECMO, \% & 1 & 1 & 4 & 13 & - & 0.001 & 1 & 1 & - & - & 0.969 \\
\hline \multicolumn{12}{|l|}{ Outcomes } \\
\hline Death, $\%$ & 20 & 18 & 11 & 38 & - & 0.196 & 18 & 22 & 33 & 17 & 0.090 \\
\hline Discharged to home, $\%$ & 62 & 66 & 77 & 50 & - & & 66 & 54 & 47 & 67 & \\
\hline Discharged to SNF, \% & 17 & 14 & 11 & 13 & - & & 14 & 22 & 20 & 17 & \\
\hline Still hospitalized, \% & 1 & 1 & 1 & - & - & & 1 & 2 & - & - & \\
\hline \multicolumn{12}{|c|}{ B. Peak ALT and ALP values } \\
\hline Mean LOS, days (SD) & $10(10)$ & $12(12)$ & $18(13)$ & $21(14)$ & $20(13)$ & $<0.001$ & $11(10)$ & $18(14)$ & $25(17)$ & $23(16)$ & $<0.001$ \\
\hline \multicolumn{12}{|l|}{ Critical care needs } \\
\hline ICU admission, \% & 31 & 42 & 65 & 84 & 88 & $<0.001$ & 38 & 63 & 82 & 77 & $<0.001$ \\
\hline ICU LOS, days (SD) & $9(9)$ & $19(11)$ & $15(10)$ & $15(10)$ & $16(12)$ & $<0.001$ & $10(9)$ & $15(12)$ & $18(10)$ & $20(13)$ & $<0.001$ \\
\hline Mech. ventilation, $\%$ & 2 & 29 & 54 & 73 & 79 & $<0.001$ & 25 & 53 & 79 & 70 & $<0.001$ \\
\hline Vasopressors, \% & 17 & 24 & 46 & 64 & 70 & $<0.001$ & 20 & 48 & 69 & 66 & $<0.001$ \\
\hline ECMO, \% & 0.5 & 0.1 & 2 & 7 & 9 & $<0.001$ & 1 & 2 & 5 & 4 & $<0.001$ \\
\hline Outcomes & & & & & & & & & & & $<0.001$ \\
\hline Death, $\%$ & 19 & 17 & 19 & 18 & 58 & $<0.001$ & 14 & 28 & 37 & 41 & \\
\hline Discharged to home, $\%$ & 66 & 69 & 60 & 55 & 28 & & 73 & 50 & 30 & 30 & \\
\hline Discharged to SNF, \% & 14 & 13 & 20 & 27 & 14 & & 12 & 19 & 31 & 29 & \\
\hline Still hospitalized, \% & 1 & 2 & 1 & - & - & & 1 & 3 & 2 & 2 & \\
\hline
\end{tabular}

Abbreviations: $\mathrm{ALP}=$ alkaline phosphatase, $\mathrm{ALT}=$ alanine aminotransferase, $\mathrm{ECMO}=$ extracorporeal membrane oxygenation, $\mathrm{LOS}=$ length of stay, $\mathrm{SNF}=$ skilled nursing facility, $\mathrm{ULN}=$ upper limit of normal

\section{Association Between Discharge to SNF and Peak Abnormal ALT and ALP}

In a subgroup analysis that only included patients who were discharged, moderate-to-severe elevations in ALT were not associated with discharge to SNF in fully adjusted regression models. However, patients who had elevations in ALP were more likely to be discharged to SNF and the magnitude of the association increased with severity of ALP elevation (1-2×ULN: OR 1.6, $p=0.001 ; 2-3 \times \mathrm{ULN}$ : OR 2.6, $p=0.025 ;>3 \times \mathrm{ULN}:$ OR $5.3, p<0.001)$.

\section{Severe ALI in COVID-19}

Only 1 patient $(0.1 \%)$ had severe ALI on hospital admission, while 25 patients ( $2 \%$ ) had severe ALI based on peak laboratory values. None of the patients met criteria for ALF defined by the absence of underlying liver disease, new ALI, and hepatic encephalopathy. [21] On average, patients with severe ALI were aged $61 \pm 14$ years old, $68 \%$ male, and $68 \%$ African-American. Twenty-three (92\%) had chronic medical conditions. Average peak AST, ALT, ALP, and total bilirubin levels were 3,625 $\pm 4,166 \mathrm{U} / \mathrm{L}, 1,561 \pm 1,498 \mathrm{U} / \mathrm{L}, 276 \pm 203$ $\mathrm{U} / \mathrm{L}$, and $5.2 \pm 5.6 \mathrm{mg} / \mathrm{dL}$, respectively. The suspected etiology of severe ALI was shock liver in 44\%, drug-induced liver injury in $4 \%$, and reported as "unknown" in the remainder. Based on the individual clinical picture of the patients with severe ALI, none were suspected by site investigators to have had liver injury as a result of direct SARS-CoV-2 injury (Supplementary Table 7). Notably, the mortality in this group was $60 \%(15 / 25)$. Only $24 \%$ of patients were discharged home.

Development of severe ALI was independently associated on multivariate regression with need for vasopressors, leukocytosis, thrombocytopenia, and African-American race (Table 2). Patients who developed severe ALI were more likely to have had severe COVID-19 given frequent 
Fig. 2 Kaplan-Meier curves evaluating in-hospital mortality based on admission liver tests and pattern of liver injury
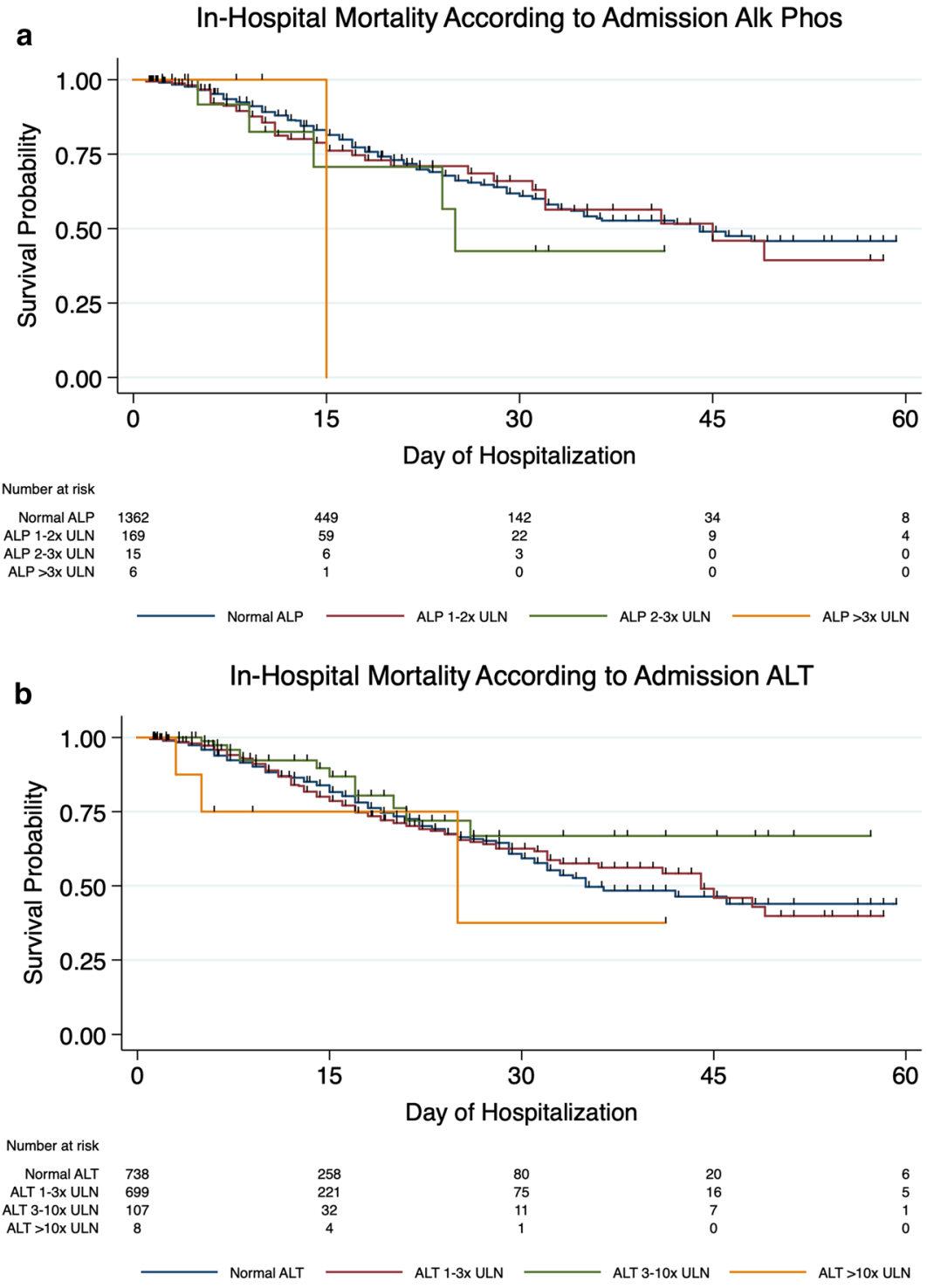

c In-Hospital Mortality According to Admission Liver Injury Pattern

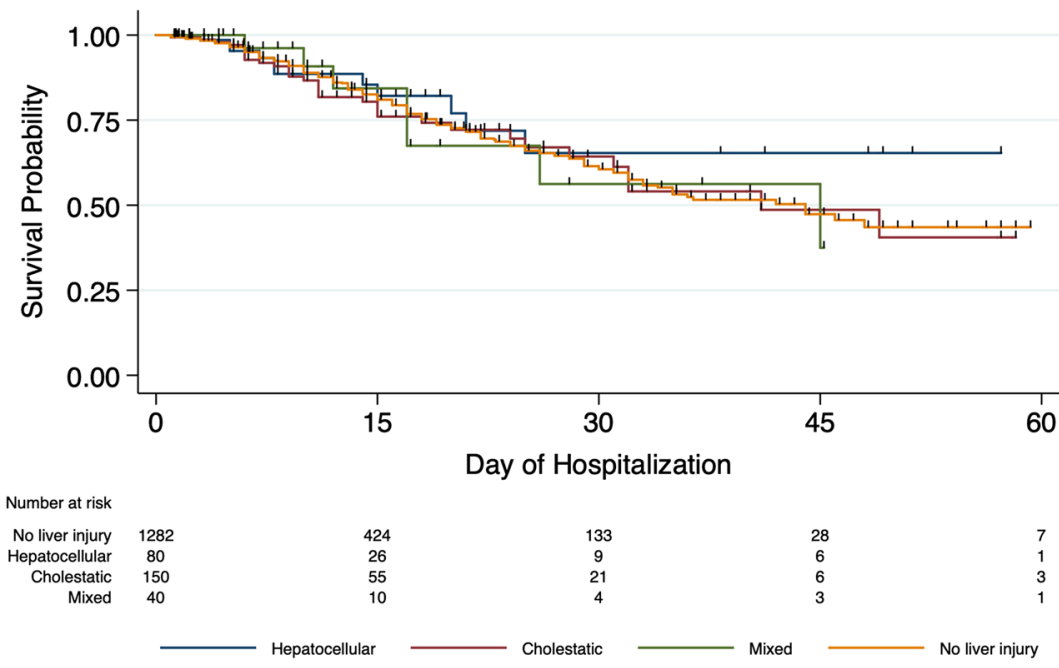


Table 4 Association Between Liver Test Abnormalities and Outcomes in Hospitalized Patients with COVID-19

\begin{tabular}{|c|c|c|c|c|c|c|c|c|}
\hline & \multicolumn{2}{|l|}{ Unadjusted } & \multicolumn{2}{|c|}{$\begin{array}{l}\text { Model } 1 \text { (demographic vari- } \\
\text { ables) * }\end{array}$} & \multicolumn{2}{|c|}{$\begin{array}{l}\text { Model } 2 \text { (model } 1+\text { comor- } \\
\text { bidity Variables) } * *\end{array}$} & \multicolumn{2}{|c|}{$\begin{array}{l}\text { Model } 3 \text { (models } 1 \text { and } \\
2+\text { severe illness variables) } \\
* * *\end{array}$} \\
\hline & OR $(95 \% C I)$ & p-value & $O R(95 \% C I)$ & p-value & OR $(95 \% C I)$ & p-value & $O R(95 \% C I)$ & p-value \\
\hline \multicolumn{9}{|c|}{ A. Association with in-hospital mortality } \\
\hline \multicolumn{9}{|l|}{ Peak ALT } \\
\hline Normal & Reference & & Reference & & Reference & & Reference & \\
\hline $1-3 \times U L N$ & $0.9(0.6-1.2)$ & 0.305 & $0.9(0.7-1.3)$ & 0.730 & $1.1(0.7-1.5)$ & 0.736 & $0.8(0.5-1.2)$ & 0.213 \\
\hline $3-10 \times \mathrm{ULN}$ & $1.0(0.7-1.4)$ & 0.912 & $1.3(0.9-1.9)$ & 0.222 & $1.7(1.1-2.5)$ & 0.014 & $0.6(0.4-1.01)$ & 0.055 \\
\hline $10-20 \times \mathrm{ULN}$ & $1.0(0.4-2.1)$ & 0.911 & $1.3(0.6-3.1)$ & 0.537 & $1.5(0.6-4.0)$ & 0.432 & $0.4(0.2-1.3)$ & 0.132 \\
\hline$>20 \times$ ULN & $6.0(3.1-11.5)$ & $<0.001$ & $7.1(3.1-14.2)$ & $<0.001$ & $7.8(3.7-16.3)$ & $<0.001$ & $2.2(0.9-5.4)$ & 0.075 \\
\hline \multicolumn{9}{|l|}{ Peak ALP } \\
\hline Normal & Reference & & Reference & & Reference & & Reference & \\
\hline $1-2 \times U L N$ & $2.4(1.8-3.2)$ & $<0.001$ & $2.7(2.0-3.7)$ & $<0.001$ & $2.8(2.0-3.8)$ & $<0.001$ & $1.4(0.9-2.1)$ & 0.064 \\
\hline $2-3 \times U L N$ & $3.8(2.2-6.4)$ & $<0.001$ & $4.2(2.4-7.4)$ & $<0.001$ & $4.7(2.6-8.6)$ & $<0.001$ & $1.6(0.8-3.1)$ & 0.149 \\
\hline$>3 \times \mathrm{ULN}$ & $4.4(2.5-7.7)$ & $<0.001$ & $5.1(2.8-9.3)$ & $<0.001$ & $4.8(2.5-9.4)$ & $<0.001$ & $2.0(0.9-4.2)$ & 0.067 \\
\hline Severe ALI & $6.8(3.0-15.3)$ & $<0.001$ & $7.4(3.1-17.7)$ & $<0.001$ & $7.3(3.0-17.8)$ & $<0.001$ & $2.8(1.01-7.9)$ & 0.047 \\
\hline \multicolumn{9}{|c|}{ B. Association with hospital LOS } \\
\hline \multicolumn{9}{|l|}{ Peak ALT } \\
\hline Normal & Reference & & Reference & & Reference & & Reference & \\
\hline $1-3 \times \mathrm{ULN}$ & $2.4(0.9-3.8)$ & 0.001 & $2.7(1.3-4.2)$ & $<0.001$ & $2.6(1.2-4.1)$ & $<0.001$ & $1.6(0.4-2.9)$ & 0.012 \\
\hline $3-10 \times \mathrm{ULN}$ & $7.7(6.0-9.4)$ & $<0.001$ & $8.3(6.6-10.0)$ & $<0.001$ & $8.6(7.0-10.3)$ & $<0.001$ & $4.3(2.8-5.9)$ & $<0.001$ \\
\hline $10-20 \times \mathrm{ULN}$ & $11.1(7.4-14.8)$ & $<0.001$ & $11.7(8.0-15.4)$ & $<0.001$ & $11.3(7.5-15.1)$ & $<0.001$ & $5.0(1.6-8.4)$ & 0.004 \\
\hline$>20 \times \mathrm{ULN}$ & $10.2(6.4-14.0)$ & $<0.001$ & $10.1(6.4-13.9)$ & $<0.001$ & $9.9(6.2-13.5)$ & $<0.001$ & $2.8(-0.6-6.1)$ & 0.107 \\
\hline \multicolumn{9}{|l|}{ Peak ALP } \\
\hline Normal & Reference & & Reference & & Reference & & Reference & \\
\hline $1-2 \times U L N$ & $7.5(6.2-8.8)$ & $<0.001$ & $7.7(6.3-9.1)$ & $<0.001$ & $7.2(5.8-8.6)$ & $<0.001$ & $3.8(2.4-5.1)$ & $<0.001$ \\
\hline $2-3 \times U L N$ & $13.9(11.2-16.6)$ & $<0.001$ & 13.7 (10.9-16.6) & $<0.001$ & $11.7(8.8-14.6)$ & $<0.001$ & $5.3(2.6-7.9)$ & $<0.001$ \\
\hline$>3 \times \mathrm{ULN}$ & $11.8(8.8-14.8)$ & $<0.001$ & $11.9(8.8-15.0)$ & $<0.001$ & $11.7(8.5-14.9)$ & $<0.001$ & $6.4(3.5-9.3)$ & $<0.001$ \\
\hline Severe ALI & $3.3(-1.6-8.2)$ & 0.185 & $2.8(-2.1-7.7)$ & 0.259 & $3.3(-1.5-8.1)$ & 0.180 & $-3.8(-8.0-0.4)$ & 0.073 \\
\hline
\end{tabular}

Abbreviations:ALI = acute liver injury, $\mathrm{ALP}=$ alkaline phosphatase, $\mathrm{ALT}=$ alanine aminotransferase, $\mathrm{CI}=$ confidence interval, $\mathrm{OR}=\mathrm{odd}$ ratio, $\mathrm{ULN}=$ upper limit of normal

* Model 1 adjusted for age (per 10 years), sex, race, Hispanic ethnicity, smoking, and alcohol use

** Model 2 adjusted for model 1 variables plus body mass index (per 5 units), hypertension, diabetes mellitus, cardiovascular disease, chronic lung disease, end-stage liver disease, cancer, dementia, connective tissue disease, HIV infection, and chronic liver disease

${ }^{* * *}$ Model 3 adjusted for models 1 and 2 variables plus acute kidney injury, need for vasopressors, need for mechanical ventilation, and need for ECMO

admissions to intensive care $(84 \%$ vs $47 \%, p<0.001)$, mechanical ventilation ( $80 \%$ vs $35 \%, p<0.001)$, vasopressor use $(80 \%$ vs $30 \%, p<0.001)$, and ECMO use $(12 \%$ vs $1 \%, p<0.001)$. The in-hospital mortality rate in patients with severe ALI was over 3 times higher than in those without severe ALI (60\% vs. 19\%, $p<0.001)$. On multivariable regression, severe ALI was associated with increased inhospital mortality (OR 2.8, 95\%CI 1.01-7.9, $p=0.047$ ), but the magnitude of the association was reduced after adjusting for covariables of hemodynamic instability and organ failure. Severe ALI was not associated with hospital LOS or discharge to a skilled care facility.

\section{Discussion}

In this large and geographically diverse cohort of hospitalized patients with confirmed COVID-19, we found that many patients presented with mild elevation in ALT on admission and $10 \%$ presented with mild elevation in ALP. The overall likelihood of developing very high elevations in ALT or ALP was extremely low (3\% and 4\%, respectively), and no patient met criteria for ALF.

The prevalence of liver injury in our study is similar to other studies that have examined abnormal liver enzymes in patients with COVID-19 [8, 22, 23]. It is crucial to highlight 
that none of the patients had severe elevations in ALT and ALP on admission, and other studies have noted similar findings $[8,12]$. This suggests that severe elevations in liver enzymes are likely due to severe inflammatory response and hemodynamic instability that are characteristic of COVID-19 rather than SARS-CoV-2 hepatotropism and related viral hepatitis or cholestatic disease [24-27]. This is further supported by our findings that factors such as leukocytosis, thrombocytopenia, vasopressor requirement, and renal dysfunction, which correlate with severe sepsis and hemodynamic instability, are associated with greater hepatocellular injury and cholestasis and the occurrence of severe ALI [28, 29].

A critical finding in our study was that severe ALI was particularly uncommon, and no patients in our cohort met formal criteria for ALF. We speculate that the majority of patients who developed severe ALI most likely had shock liver and/or multisystem organ failure. Shock liver was specifically identified as the etiology of severe ALI in 11 patients (44\%), and moreover, among the 14 patients in whom the etiology of severe ALI was not specified, nine (64\%) required vasopressors. In aggregate, the data lead us to speculate that markedly abnormal ALT levels in patients with COVID-19 are most likely simply a marker of severe underlying systemic disease and that COVID-19 is not a cause of severe primary acute viral hepatitis as has been hypothesized in previous case reports. [13-15]

Severe elevation in ALT and ALP and severe ALI were associated with increased in-hospital mortality. That the strength of these associations was attenuated or statistical significance was lost after adjusting for variables related to hemodynamic instability and critical illness demonstrate that elevated liver enzymes and liver injury per se do not predict death or indicate viral hepatitis or cholestatic liver disease due to SARS-CoV-2, but are best regarded as markers of severe COVID-19. In keeping with this proposition that liver injury is a marker of severe COVID-19, we also observed longer hospital LOS in patients with elevated ALT and ALP and increased likelihood of discharge to SNF in patients with elevated ALP in the fully adjusted regression models. Patients with very severe elevations in ALT had a shorter hospital LOS than patients with mild-to-severe elevations in ALT in the fully adjusted model. This finding is probably due to high in-hospital mortality and poor prognosis in this patient group, which translates to fewer hospitalization days.

We recognize the limitations of this study. First, data collection was retrospective. Additionally, contributing centers were not required to obtain abdominal imaging or comprehensive serologic testing in order to evaluate the etiology of abnormal liver enzymes. The primary liver enzyme measurements recorded were those on admission and peak values during hospitalization. Therefore, temporal trends in liver enzymes in relation to medications, clinical status, or other critical events could not be determined. However, we utilized multiple approaches to overcome these limitations including rigorous data collection and quality assurance processes employed by participating centers and monitored by the data coordinating center. Further, for all cases of severe ALI, contributing centers were also contacted individually to obtain their expert opinion on the etiology of liver injury. The study is also subject to selection bias since all study patients were hospitalized and had more severe COVID-19. The findings may not be generalizable to patients with less severe COVID-19. For example, demonstration of new liver test elevations in a patient with milder COVID-19 raises the possibility of SARS-CoV-2 hepatotropism.

In summary, abnormal liver tests are frequently identified in patients hospitalized with COVID-19. The majority of these abnormalities are mild elevations in ALT or ALP. More severe elevations in ALT levels occur in a subset of patients with severe COVID-19, typically those with hemodynamic instability, systemic inflammation, severe sepsis, and multiorgan failure. Severe ALI is rare and typically due to shock liver rather than SARS-CoV-2 viral hepatitis, and ALF does not appear to be a complication of COVID-19.

\section{Financial Support}

DCR supported by the NIDDK, Grant P30 DK 123704.

\section{Appendix}

First author Lindsay A. Sobotka DO

Senior author Don C. Rockey MD

Primary authors Lindsay A. Sobotka DO, James Esteban MD, Michael L. Volk MD, MSc, B.Joseph Elmunzer MD, Don C. Rockey MD.

\section{Statisticians James Esteban MD}

Data Coordinating Center Teldon B. Alford BA, Haley Nitchie MHA, Collins O. Ordiah MBBS, Rebecca L. Spitzer MPH, Lauren Wakefield MHA.

Steering Committee Olga C. Aroniadis MD, Darwin L. Conwell MD, Amar R. Deshpande MD, Christopher J. DiMaio MD, Rebekah E. Dixon BS, B. Joseph Elmunzer MD (Chair), Jennifer M. Kolb MD, Robin B. Mendelsohn MD, Raman Muthusamy MD, Collins O. Ordiah MBBS, MS, Swati Pawa MD, MSc, MAS, Don C. Rockey MD, Rebecca L. Spitzer MPH, William M. Tierney MD, Sachin Wani MD, Dhiraj Yadav MD, MPH. 


\section{Clinical sites in order of number of patients contributed}

Emory University Ambreen A. Merchant MBBS, Vaishali A. Patel MD, Field F. Willingham MD, MPH.

Vanderbilt University Eric F. Howard RN, BSN, Mary K. West RN, BSN, Casey L Koza BS, Patrick S. Yachimksi MD.

Grady Memorial Hospital Emad Qayed MD, MPH, Rosemary Nustas MD.

Ascension Providence Hospital/Michigan State University Ali Zakaria MD, Marc S. Piper MD, MSc.

Saint Louis University Jason R. Taylor MD, Lujain Jaza MD.

University of Calgary Nauzer Forbes MD, MSc, Millie Chau BSc.

The Ohio State University Wexner Medical Center Luis F. Lara MD, Georgios I. Papachristou MD, PhD, Uchechi Okafor BSc, Darwin L. Conwell MD, MSc.

Loma Linda University Michael L. Volk MD, MSc, Evan Mosier MD, Mohamed Azab MD, Anish Patel MD.

University of Southern California Liam G. Hilson MD, Selena Zhou MD, James Buxbaum MD.

Washington University School of Medicine Vladimir M. Kushnir MD, Alexandria M. Lenyo BS, Ian P. Sloan BS, Thomas Hollander RN, BSN.

Medical University of South Carolina Caroline G. McLeod BS, Rebecca L. Spitzer MPH, Lauren Wakefield MHA (1), Haley Nitchie MHA, Collins O. Ordiah MBBS, MPH, Don C. Rockey MD, B. Joseph Elmunzer MD.

University of Miami Miller School of Medicine Sunil Amin MD, MPH, Gabriela N. Kuftinec MD, MPH, Amar R. Deshpande MD.

University of Pittsburgh Dhiraj Yadav MD, MPH, Melissa Saul MS (14), Melanie Mays BS (14), Gulsum Anderson PhD (14), Kelley Wood BS (14), Laura Mathews BS (14).

University of Colorado Charlie Fox MD (15) Jennifer M. Kolb MD, MS, Sachin Wani MD.
Wake Forest University School of Medicine Swati Pawa MD, Rishi Pawa MD.

Boston University Andrew Canakis DO, Christopher Huang MD.

Beaumont Health Laith H. Jamil MD, Andrew M. Aneese MD, V. Mihajlo Gjeorgjievski, MD, Zaid Imam MD, Fadi Odish MD, Ahmed I. Edhi MD, Molly Orosey DO, Abhinav Tiwari MD, Soumil Patwardhan MBBS.

University Hospitals of Cleveland Medical Center Benita K. Glamour BA, Zachary L Smith DO, Amy E. Hosmer MD, Nancy Furey RN, BSN, MBA, Amitabh Chak MD.

Northwestern University Feinberg School of Medicine Katherine A. Hanley MMS, PAC, Jordan Wood BS, Rajesh N. Keswani MD, MS.

Ochsner Health Harsh K. Patel MBBS, Janak N. Shah MD.

Columbia University Medical Center Emil Agarunov BS, Nicholas G. Brown MD, Anish A. Patel MD, Amrita Sethi MD.

Indiana University School of Medicine Evan L. Fogel MD, MSc, Gail McNulty RN, BSN.

Loyola University Medical Center Abdul Haseeb MD, Judy A. Trieu MD.

Icahn School of Medicine at Mount Sinai Rebekah E. Dixon BS, Jeong Yun Yang MD, Christopher J. DiMaio MD.

Memorial Sloan Kettering Cancer Center Robin B. Mendelsohn MD, Delia Calo MD.

Renaissance School of Medicine at Stony Brook University Olga C. Aroniadis MD, MSc, Joseph F. LaComb BS, Lilian Cruz BS, Olga Reykhart BS.

University of Virginia Medical School James M. Scheiman MD, Bryan G. Sauer MD, Galina Diakova MS.

Henry Ford Health System Duyen T. Dang MD, Cyrus R. Piraka MD.

Dartmouth-Hitchcock Health and VA White River Junction Eric D. Shah MD, MBA, Molly Caisse BS, Natalia H. Zbib MD (31), John A. Damianos MD, Heiko Pohl MD. 
University of Oklahoma Health Sciences Center William M. Tierney MD, Stephanie Mitchell RN, Michael S. Bronze MD.

David Geffen School of Medicine at UCLA Ashwinee Condon MD (34), Adrienne Lenhart MD, Raman Muthusamy MD, MAS.

Medical College of Wisconsin Kulwinder S. Dua MD, Vikram S. Kanagala MD, James Esteban MD.

Johns Hopkins Medical Institutions Ayesha Kamal MD, Marcia I. Canto MD, Vikesh K. Singh MD, MS.

McMaster University Hamilton Health Sciences Maria Ines Pinto-Sanchez MD, MSc (37), Joy M. Hutchinson RD, MSc.

Michigan Medicine Richard S. Kwon MD (38), Sheryl J. Korsnes MA.

University of Manitoba Harminder Singh MD, MPH, Zahra Solati MSc, Nick Hajidiacos MD.

Supplementary Information The online version contains supplementary material available at https://doi.org/10.1007/ s10620-021-07230-9.

\section{Declarations}

Conflict of interest None of the authors have potential competing interests.

\section{References}

1. Zhu N, Zhang D, Wang W et al. A Novel Coronavirus from Patients with Pneumonia in China, 2019. The New England Journal of Medicine. 2020;382:727-733.

2. Munster VJ, Koopmans M, van Doremalen N et al. A Novel Coronavirus Emerging in China-Key Questions for Impact Assessment. The New England Journal of Medicine. 2020;382:692-694.

3. Zhou F, Yu T, Du R et al. Clinical course and risk factors for mortality of adult patients with COVID-19 in Wuhan, Chine: a retrospective cohort study. Lancet. 2020;395:1054-1062.

4. Guan Wj, Ni Z, Hu Y, et al. Clinical Characteristics of Coronavirus Disease 2019 in China. The New England Journal of Medicine. 2020; 382:1708-1720.

5. Elmunzer BJ, Spitzer RL, Foster LD, et al. Digestive Manifestations in Patients Hospitalized with COVID-19. Clin Gastroenterol Hepatol. 2020.

6. Herold T, Jurinovic V, Arnreich C et al. Level of IL-6 predicts respiratory failure in hospitalized symptomatic COVID-19 patients. Journal of Allergy and Clinical Immunology. 2020;14:128-136.

7. Tian J, Yuan XY, Xiao J et al. Clinical characteristics and risk factors associated with COVID-19 disease severity in patients with cancer in Wuhan China: a multicentre, retrospective, cohort study. The Lancet Oncology. 2020;21:893-903.
8. Cai Q, Huang D, Yu H et al. COVID-19: Abnormal liver function tests. Journal of Hepatology. 2020;73:566-574.

9. Chai X, Hu L, Zhang Y, et al. Specific ACE2 expression in cholangiocytes may cause liver damage after 2019-nCoV infection. BioRxiv. 2020.

10. Chen N, Zhou M, Dong X et al. Epidemiologic and clinic characteristics of 99 cases of 2019 novel coronavirus pneumonia in Wuhan, China: a descriptive study. Lancet 2020;395:507-513.

11. Wang D, Hu B, Hu C, et al. Clinical characteristics of 138 hospitalized patients with 2019 novel coronovirus-infected pneumonia in Wuhan China 2020;323:1061-1069.

12. Ali N. Relationship Between COVID-19 Infection and Liver Injury: A Review of Recent Data. Front Med 2020;7:458.

13. Gurala D, Moussawi HA, Philipose J, et al. Acute Liver Failure in a COVID-19 Patients Without any Preexisting Liver Disease. Cureus 2020;12:e10045

14. Weber S, Mayerle J, Irlbeck $M$ et al. Severe liver failure during SAR-CoV-2 infection. Gut 2020;69:1365-1367.

15. Sarkar S, Rapista N, Jean LG. Coronavirus Disease-19-Induced Acute Liver Failure Leading to Severe Metabolic Acidosis. Chest 2020;158:a1002

16. Vilstrup H, Amodio P, Bajaj J et al. Hepatic encephalopathy in chronic liver disease: 2014 Practice Guidelines by the American Association for the Study of Liver Diseases and the European Association for the Study of the Liver. Hepatology 2014;60:715-735.

17. Clark JM, Brancati JM, Diehl AM. Nonalcoholic fatty liver disease. Gastroenterology 2020;122:1649-1657.

18. American Gastroenterologic Association. Medical position statement: evaluation of liver chemistry tests. Gastroenterology 2002:123:1364-1366.

19. Gonzalez HC, Imam Z, Wong R, et al. Normal alkaline phosphatase levels are dependent on race/ethnicity: National Health and Nutrition Examination Survey Data. BMJ Open Gastroenterology 2020;7:e000502

20. Robles-Diaz M, Lucena MI, Kaplowitz N et al. Use of Hy's Law and a New Composite Algorithm to Predict Acute Liver Failure in Patients with Drug-Induced Liver Injury. Gastroenterology 2014;147:109-118.

21. Lee WM, Squires RH, Nyberg SL et al. Acute liver failure: summary of a workshop. Hepatology 2008;47:1401-1415.

22. Phipps MM, Barraza LH, LaSota ED, et al. Acute Liver Injury in COVID-19:Prevalence and Association with Clinical Outcomes in a Large U.S.Cohort. Hepatology 2020;72:807-817.

23. Da BL, Kushner T, El Halabi M et al. Liver Injury in Patients Hospitalized with Coronovirus Disease 2019 Correlates with Hyperinflammatory Response and Elevated Interleukin-6. Hepatology Communications 2020;5:177-188.

24. Bertolini A, van de Peppel IP, Bodewes FAJA et al. Abnormal Liver Function Tests in Patients with COVID-19: Relevance and Potential Pathogenesis. Hepatology 2020;72:1864-1872.

25. Wiersinga WJ, Rhodes A, Cheng A, et al. Pathophysiology, Transmission, Diagnossi, and Treatment of Coronavirus Disease 2019 (COVID-19): A Review 2020;324:782-793.

26. Chand N, Sanyal AJ. Sepsis-Induced Cholestasis. Hepatology 2007;45:230-241.

27. Guglielmi FW, Regano N, Mazzuoli S et al. Cholestasis Induced by Total Parental Nutrition. Clinical Liver Diseases 2008;12:97-110.

28. Darkas JD. The Complete Blood Count to Diagnose Septic Shock. Journal of Thoracic Disease 2020;12:S16-S21.

29. Auchet T, Regnier MA, Girerd N et al. Outcome of Patients with Septic Shock and High-Dose Vasopressor Therapy. 2017;7:43.

Publisher's Note Springer Nature remains neutral with regard to jurisdictional claims in published maps and institutional affiliations. 